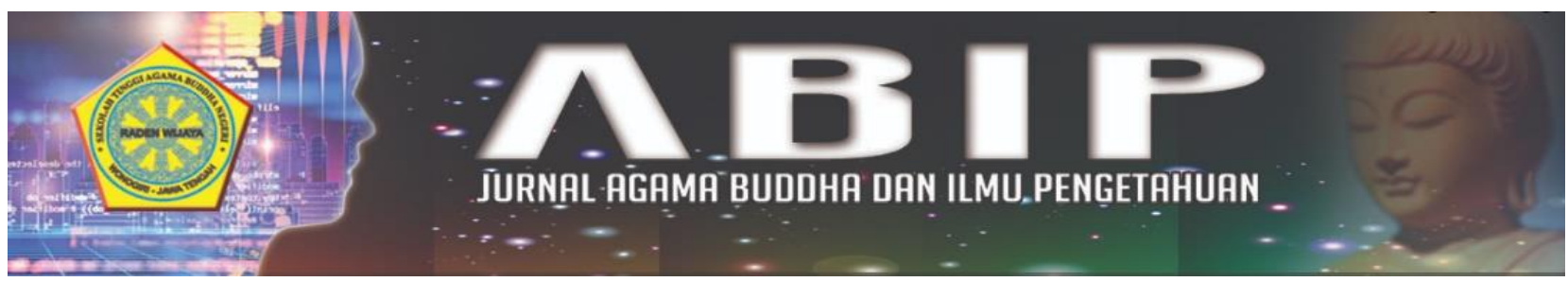

\title{
PERBEDAAN PENGARUH PENGGUNAAN MEDIA SCRABBLE SECARA KELOMPOK DAN SECARA INDIVIDU TERHADAP PENINGKATAN PENGETAHUAN FAKTUAL KATA ISTILAH MAHASISWA STAB MAHA PRAJNA
}

\author{
Oleh: \\ Andhika Mustika Dharma, Wahyu Diono Duta Kshanti, Sumiyatun, \\ Melinda Kanti Surya Kumara \\ Sekolah Tinggi Agama Buddha Maha Prajna \\ andhikamustikadharma@gmail.com
}

\begin{abstract}
Penelitian ini bertujuan untuk mengetahui perbedaan pengaruh penggunaan media scrabble secara kelompok dan individu terhadap pengetahuan faktual kata istilah pada mahasiswa STAB Maha Prajna yang idealnya mahasiswa memiliki pengetahuan faktual yang baik bila terus diasah. Penelitian ini menggunakan eksperimen semu, dengan membagi menjadi dua kelompok, yaitu kelompok I dan kelompok II. Kelompok eksperimen I dengan perlakuan penggunaan scrabble berkelompok dan kelompok II dengan perlakukan penggunaan scrabble individual. Populasi dalam penelitian ini adalah seluruh mahasiswa STAB Maha Prajna Cilincing yang berjumlah 55 mahasiswa dari semester 1, 3, 5 dan 7. Peneliti menggunakan metode probability sampling yaitu menentukan sampel secara acak atau random dari populasi yang ada, yaitu semester 1 yang berjumlah 19 mahasiswa dan sebagian semester 3 yang berjumlah 11 mahasiswa. Metode yang digunakan adalah metode survei dan teknik pengumpulan datanya menggunakan tes dan pengukuran. Instrumen yang digunakan adalah tes pengetahuan faktual kata istilah pada materi Ilmu Alamiah Dasar. Analisis data menggunakan uji t. Hasil penelitian menunjukkan bahwa: (1) ada perbedaan signifikan pada kelompok eksperimen berkelompok, dengan $t$ hitung 7,83228 > t tabel 2.145, dan nilai signifikasi 0,000 $<0.05$. (2) Ada perbedaan signifikan pada kelompok eksperimen individual, dengan t hitung $6.809>t$ tabel 2.145, dengan nilai signifikansi $0.000<0.05$. (3) penggunaan scrabble individual lebih efektif untuk meningkatkan penguasaan faktual kata istilah, kenaikan persentase kelompok pengguna media scrabble berkelompok sebesar 112,847\% dan kenaikan persentase kelompok eksperimen individual sebesar $79,71 \%$.
\end{abstract}

Kata kunci: penggunaan scrabble berkelompok, penggunaan scrabble individual, penguasaan faktual kata istilah.

\begin{abstract}
This study aims to determine the difference in the effect of using scrabble media as a group and individually on the factual knowledge of terms in STAB Maha Prajna students, which ideally students have good factual knowledge if it is continuously sharpened. This research used quasi-experimental, by dividing into two groups, namely group I and group II. The experimental group I treated using scrabble in groups and group II treated the use of individual scrabble. The population in this study were all students of STAB Maha Prajna Cilincing, totaling 55 students from semesters 1, 3, 5 and 7.
\end{abstract}


Researchers used a probability sampling method, namely determining a random sample or random sample from the existing population, namely semester 1, totaling 19 students and part of the 3rd semester, totaling 11 students. The method used is a survey method and data collection techniques using tests and measurements. The instrument used is a test of factual knowledge of the terms in the Basic Natural Science material. Data analysis using $t$ test. The results showed that: (1) there was a significant difference between the experimental group and the group, with $t$ count 7.83228> $t$ table 2.145 , and a significance value of $0.000<0.05$. (2) There is a significant difference in the individual experimental group, with t count 6.809> t table 2.145, with a significance value of $0.000<0.05$. (3) the use of individual scrabble is more effective to improve factual mastery of word terms, an increase in the percentage of scrabble media users in groups of $112.847 \%$ and an increase in the percentage of individual experimental groups by $79.71 \%$.

Keywords: group scrabble use, individual scrabble use, factual mastery of word terms.

\section{PENDAHULUAN}

Dalam pemenuhan pendidikan yang terus berkembang, penggunaan media pembelajaran sangat membantu pengajar dalam menyampaikan materi sekaligus menjadikan pembelajaran lebih bervariasi. Menurut Oemar Hamalik (2015:57) pembelajaran adalah suatu kombinasi yang tersusun meliputi unsur-unsur manusiawi, material, fasilitas, perlengkapan, dan prosedur yang saling mempengaruhi mencapai tujuan pembelajaran. Jamil Suprihatiningrum (2013: 75) mengungkapkan bahwa pembelajaran adalah serangkaian kegiatan yang melibatkan informasi dan lingkungan yang disusun secara terencana untuk memudahkan siswa dalam belajar. Lingkungan yang dimaksud tidak hanya berupa tempat, tetapi juga metode, media, dan peralatan yang diperlukan untuk menyampaikan informasi. Berdasarkan pendapat tersebut diketahui bahwa pembelajaran membutuhkan fasilitas, perlengkapan dan lingkungan yang disusun secara terencana. Lingkungan ini termasuk penggunaan media dan peralatan.

Menurut Moh. Uzer Usman, mengajar adalah suatu usaha mengorganisasi lingkungan dalam hubungannya dengan siswa dan bahan pembelajaran sehingga menimbulkan proses belajar mengajar pada diri siswa (dalam Nunuk Suryani dan Leo Agung 2012: 36). Dengan ini penggunaan media dibutuhkan sebagai upaya mempermudah penguasaan materi pada mata kuliah oleh mahasiswa. Pentingnya peran dari media pembelajaran ini, menjadikan dosen atau pengajar menentukan media yang sesuai pada mata kuliah masing-masing.

Dalam penguasaan materi mata kuliah, pengetahuan faktual kata istilah perlu untuk ditingkatkan. Pengetahuan faktual merupakan pengetahuan yang harus dimiliki peserta didik jika mereka akan dikenalkan dengan suatu disiplin ilmu atau untuk memecahkan masalah apapun di dalamnya yang berkaitan dengan pernyataan yang benar karena sesuai dengan kenyataan yang sebenarnya (Anderson \& Krathwohl, 2017:46). Pengetahuan faktual berkaitan dengan pernyataan yang benar karena sesuai dengan keadaan yang sesungguhnya. Idealnya, mahasiswa yang sudah memiliki pengetahuan faktual tentang kata istilah, akan lebih memahami dibandingkan mahasiswa yang belum memiliki pengetahuan faktual tentang kata istilah yang sedang dibahas dalam materi. Mahasiswa yang belum menguasai pengetahuan faktual kata istilah, akan berupaya memahami dahulu kata istilah tersebut, baru kemudian memahami materi yang disampaikan. Tanpa pengetahuan faktual kata istilah, mahasiswa cenderung akan meraba-raba materi yang diterima. Kondisi ini menjadikan dosen harus menerangkan terlebih dahulu pengertian dari masing-masing kata istilah yang tersampaikan dalam materi, agar proses belajar mengajar dapat sepenuhnya dikuasai mahasiswa. Dengan ini efektifitas pengajaran menjadi berkurang atau tidak maksimal. Sebab dapat mengkondisikan proses belajar, melenceng dari RPP yang digunakan. 
Scrabble telah banyak dikembangkan menjadi media pembelajaran. Menurut Heinich and Molenda, mengemukakan bahwa "Scrabble is an activity in which participants allow prescribed rules that a differ from those of real as they strives to attain a challenging goal" (Jurnal Cherleyrian Ningsih). Oleh karena itu pembelajaran menggunakan scrabble menggabungkan aspek kognitif, afektif, psikomotor, logika, emosional/sosial, kreatif/imajinatif sehingga pembelajaran akan lebih bermakna dan menyenangkan. Scrabble dapat diterapkan untuk menyampaikan pesan dalam berbagai ilmu pengetahuan, dan karena penampilannya yang menarik, format dalam scrabble ini seringkali diberikan pada penjelasan yang sungguh-sungguh dari pada sifat yang hiburan semata (Jurnal Cherleyrian Ningsih).

Media scrabble sangat menarik dalam membangkitkan minat mahasiswa dalam belajar. Dengan media scrabble mahasiswa dituntut untuk berpikir kreatif dan memudahkan mahasiswa dalam memahami dan mengingat kata istilah yang disampaikan. Dalam proses belajar, seseorang belajar dari pengalaman sendiri, mengkontruksikan pengetahuan kemudian memberi makna pada pengetahuan itu. Dengan menerapkan media belajar scrabble pada proses belajar dapat membawa mahasiswa dalam belajar yang menyenangkan serta menghindari kejenuhan terhadap muatan materi yang banyak.

Scrabble has unique game characteristics that should be of interest to psychologists because they involve three major cognitive abilities that are integral for successful play: (a) verbal ability in the form of word fluency, because the game requires the rapid retrieval of appropriate words from memory; (b) visuospatial ability, because the spatial layout of words and letters on particular squares on the board determines the point value of a play; and (c) numerical ability, because players need to calculate probabilities and rapidly use the numerical properties associated with different combinations of words located in different places on the board (Journal of Experimental Psychology: Diane F. Halpern, The World of
Competitive Scrabble: Novice and Expert Differences in Visuospatial and Verbal Abilities: 2007, Vol. 13, No. 2, 79-94). Hal ini menyatakan bahwa scrabble merupakan permainan unik dan menarik yang mampu meningkatkan kemampuan kognitif pesertanya.

Dalam beberapa penelitian sebelumnya, diketahui pula penerapan media scrabble mampu membantu mahasiswa untuk menguasai kosakata pada berbagai pelajaran atau mata kuliah yang tidak hanya menggunakan bahasa Indonesia atau bahasa inggris saja, melainkan menggunakan bahasa lain seperti aksara. Dengan ini media scrabble dapat digunakan pada setiap penyampaian materi mata kuliah apapun. Media scrabble merupakan permainan menyusun kata dalam Bahasa Inggris yang dapat dikembangkan menjadi susunan kata ilmiah pada materi. Kosakata, aksara dan kata ilmiah erat kaitannya dengan kata istilah, ini menjadi alasan tambahan media scrabble digunakan dalam menguasai kata istilah.

Media scrabble umumnya dilakukan secara berkelompok dengan maksimal 4 peserta, dengan bersaing mendapat nilai tertinggi, namun dapat dikembangkan penggunaannya secara individu. Penggunan secara individu artinya pemain berusaha berpikir kreatif dan inovatif menyusun sendirian kata istilah untuk bersaing dengan peserta lain yang jumlahnya lebih banyak dengan tetap mengejar skor/nilai tertinggi. Kedua cara ini tidak dapat dikesampingkan dalam meningkatkan pengetahuan faktual kata istilah secara maksimal. Artinya dapat dilakukan ujicoba atau praktek penggunaan media scrabble secara berkelompok dan juga secara individual pada mata kuliah.

Media pembelajaran dengan peran meningkatkan kreatif dan mempermudah penguasaan materi dengan pengalaman langsung, yang bermanfaat mengasah kemampuan otak, menjadi suatu kombinasi menarik yang sulit diacuhkan begitu saja oleh mahasiswa. Manfaat dari penggunaan media, dibutuhkan dalam proses belajar mengajar. Hanya saja, media scrabble tersebut belum diterapkan dalam pembelajaran di STAB Maha Prajna. 
Dalam pengamatan penulis sebagai dosen STAB Maha Prajna sejak tahun 2014, penguasaan faktual kata istilah mahasiswa STAB Maha Prajna masih kurang, sehingga dalam pengajaran membutuhkan waktu lebih untuk menjelaskan kata istilah. Maka efektifitas dalam proses belajar mengajar, menjadi tidak maksimal.

Setiap materi mata kuliah, memiliki kata istilah, sehingga media scrabble dapat diterapkan pada mata kuliah manapun. Peneliti sebagai dosen Ilmu Alamiah Dasar, tentu akan menerapkan terlebih dahulu penggunaan media scrabble pada mata kuliah tersebut. Ilmu Alamiah Dasar (IAD) merupakan ilmu yang erat kaitannya dengan Ilmu Pengetahuan Alam dan Sains. Merupakan kumpulan pengetahuan tentang konsep-konsep dasar dalam bidang ilmu pengetahuan alam dan teknologi dalam manusia yang biasa disebut Natural Science. Penulis sebagai dosen IAD perlu mengembangkan metode pengajaran dengan pemanfaatan media sebagai bahan ajar dengan tujuan proses belajar mengajar terlaksana dengan menyenangkan, bervariatif dan efektif. Dengan ini diharapkan penguasaan materi akan lebih mudah.

Mengingat pentingnya penguasaan faktual kata istilah dalam pemahaman materi, maka perlu diteliti tentang perbedaan penggunaan media scrabble secara berkelompok dan individual dalam meningkatkan pengetahuan faktual kata istilah.

Media adalah alat saluran komunikasi. Kata media berasal dari bahasa Latin yang merupakan bentuk jamak dari kata medium. Secara harfiah, media berarti perantara, yaitu perantara antara sumber pesan dengan penerima pesan. Karena dalam konteks ini media digunakan untuk pengajaran di kampus, maka dinamakan media pengajaran. Dina Indriana (2011: 16) menyatakan bahwa media pengajaran yaitu semua bahan dan alat fisik yang mungkin digunakan untuk mengimplementasikan pengajaran dan memfasilitasi prestasi siswa terhadap sasaran atau tujuan pengajaran.

Media adalah alat atau bahan sebagai bagian yang tak terpisahkan dari proses belajar demi tercapainya tujuan pendidikan pada umumnya dan tujuan pembelajaran di kampus pada khususnya. Media pembelajaran dapat berupa hardware atau software yang dapat digunakan selama proses pembelajaran agar mahasiswa dapat memahami suatu materi atau keterampilan dalam suatu pembelajaran.

a. Fungsi Media Pengajaran

Hamalik (dalam Azhar Arsyad, 2006: 15) mengemukakan bahwa pemakaian media pembelajaran dalam proses belajar mengajar dapat membangkitkan keinginan dan minat baru, membangkitkan motivasi dan rangsangan kegiatan belajar, dan membawa pengaruh-pengaruh psikologis terhadap peserta didik.

Nana Sudjana dan Ahmad Rivai (2002:

2) menambahkan bahwa media pembelajaran dapat bermanfaat karena bahan pengajaran akan lebih jelas maknanya sehingga dapat lebih dipahami oleh para peserta didik dan menungkinkan peserta didik menguasai tujuan pengajaran lebih baik; metode mengajar akan lebih bervariasi, tidak semata-mata komunikasi verbal melalui penuturan kata-kata oleh dosen, sehingga peserta didik tidak bosan dan dosen tidak kehabisan tenaga, apalagi bila dosen mengajar untuk setiap jam pelajarannya; peserta didik lebih banyak melakukan kegiatan belajar, sebab tidak hanya mendengarkan uraian dosen, tetapi juga aktivitas lain seperti mengamati, melakukan, mendemonstrasikan, dan lain-lain. Pada intinya, media pengajaran sebagai alat yang dapat melengkapi kelangsungan proses belajar mengajar agar pembelajaran lebih optimal, efektif dan efisien.

b. Macam-macam Media Pembelajaran

Dalam membantu pendidik memberikan pengajaran, saat ini jenis media yang ada sudah cukup beragam, mulai dari yang sederhana sampai yang cukup rumit. Untuk mempermudah mempelajari jenis media, dilakukan pengklasifikasian atau penggolongan. Penggolongan media ini berbeda-beda sesuai dari sudut pandang apa kita menggolongkannya. Berdasarkan perkembangan teknologi, Azhar Arsyad 
(2009: 29) mengelompokkan media pembelajaran ke dalam empat jenis yaitu media hasil teknologi cetak, media hasil teknologi audio-visual, media hasil teknologi yang berdasarkan komputer, dan teknologi gabungan.

Berdasarkan penjelasan tersebut, setiap media pada dasarnya memiliki kelebihan dan kekurangan. Tidak ada media yang sempurna dan mampu untuk diaplikasikan dalam semua tujuan pembelajaran, dan sesuai dengan karakteristik semua anak didik.

Arief S. Sadiman (2009: 85) menjelaskan bahwa dalam pemilihan media pengajaran, seyogyanya tidak terlepas dari konteksnya bahwa media merupakan komponen dari sistem intruksional secara keseluruhan. Oleh karena itu ada beberapa hal yang mempengaruhi dalam pemilihan media pengajaran.

Dick dan Carey (dalam Arief S. Sadiman dkk, 2009: 86) menjelaskan empat faktor yang perlu dipertimbangkan dalam pemilihan media pengajaran, yaitu sebagai berikut.

1) Ketersediaan sumber setempat, artinya media pengajaran tersedia di sekolah atau harus membeli.

2) Apakah untuk membeli atau memproduksi media pengajaran ada dana, fasilitas, dan tenaganya.

3) Faktor keluwesan, ketahanan, dan kepraktisan media pengajaran yang digunakan. Sebuah media pengajaran hendaknya dapat digunakan berulang kali untuk waktu yang lama. Media pengajaran juga praktis dan lues agar mudah dibawa kemana-mana.

4) Efektivitas biaya dan jangka waktu yang panjang

Azhar Arsyad (2005: 75) berpendapat bahwa ada beberapa kriteria yang patut diperhatikan dalam memilih media, antara lain:

1) Sesuai dengan tujuan pembelajaran yang akan dicapai.

2) Tepat dan sesuai dengan mata pelajaran yang diajarkan sehingga dapat mendukung isi pelajaran baik fakta, konsep, prinsip, maupun generalisasi.

3) Praktis, luwes, dan bertahan lama.
4) Dosen memiliki keterampilan atau mampu menggunakannya.

5) Menentukan sasaran pengguna, apakah kelompok besar, keompok sedang, kelompok kecil, atau individu.

6) Mutu teknis harus memenuhi persyaratan tertentu.

Dalam penelitian ini, pengembangan media yang akan dilakukan adalah media visual (kartu dan papan bermain). Ada beberapa prinsip yang digunakan dalam mengembangkan produk media yang berbasis visual. Prinsipprinsip visual tersebut membuat media yang efektif dalam mengkomunikasikan pesan dan informasi sesuai dengan tujuan yang ingin dicapai. Prinsip-prinsip visual tersebut meliputi kesederhanaan (simplicity), kesatuan (unity), penekanan (emphasis), keseimbangan (balance), bentuk (shape), garis (line), ruang (space), tekstur (texture), dan warna (color) (Benny Agus Pribadi dkk, 1996: 131-135).

1) Kesederhanaan, secara umum mengacu pada jumlah elemen yang terkandung dalam suatu visual. Jumlah elemen yang lebih sedikit memudahkan siswa menangkap dan memahami pesan yang disajikan visual itu. Kata-kata harus memakai huruf yang sederhana dengan gaya huruf yang mudah terbaca dan tidak terlalu beragam. Selain itu, hindarilah bentuk tulisan yang artistik karena tidak setiap orang bisa membacanya (Deni Hardianto, 2012). Kalimatnya juga ringkas tetapi padat, dan mudah dimengerti.

2) Keterpaduan atau kesatuan, mengacu kepada hubungan yang terdapat di antara elemenelemen visual yang ketika di amati akan berfungsi secara bersamasama. Elemenelemen itu harus saling terkait dan menyatu sebagai suatu keseluruhan yang mudah dipahami.

3) Penekanan, meskipun dirancang sederhana, namun memerlukan penekanan pada salah satu unsur yang akan menjadi pusat perhatian siswa. Dengan menggunakan ukuran, hubungan-hubungan, perspektif, warna, atau ruang penekanan dapat diberikan kepada unsur terpenting.

4) Keseimbangan, bentuk atau pola yang dipilih sebaiknya menempati ruang 
penayangan yang memberikan persepsi keseimbangan meskipun tidak seluruhnya simetris. Keseimbangan ini ada dua jenis (Deni Hardianto, 2012) yaitu formal dan informal. Keseimbangan formal ditunjukkan dengan adanya pembagian secara simetris, bentuk ini terkesan statis. Sebaliknya keseimbangan informal, bentuknya tidak simetris, bentuk ini lebih dinamis dan menarik perhatian. Maka dibutuhkan imaginasi dan kreativitas dari dosen.

5) Bentuk, bentuk yang aneh dan asing bagi siswa dapat membangkitkan minat dan perhatian. Oleh karena itu, pemilihan bentuk sebagai unsur visual dalam penyajian pesan, informasi atau isi pelajaran perlu diperhatikan.

6) Ruang, untuk membuat medium visual yang efektif dalam mengkomunikasikan pesan dan informasi, diperlukan adanya pemanfaatan ruang yang baik. Pemanfaatan ruang dapat menciptakan kesan statik dan dinamik.

7) Tekstur, unsur visual yang dijadikan sebagai pengganti sentuhan rasa tertentu dan dapat juga dipakai sebagai pengganti warna, memberikan penekanan, pemisahan, atau untuk meningkatkan kesatuan.

8) Warna, memberi kesan pemisahan atau penekanan, atau untuk membangun keterpaduan. Warna dapat mempertinggi tingkat realism objek atau situasi yang digambarkan, menunjukkkan persamaan dan perbedaan, dan menciptakan respons emosional tertentu. Ada tiga hal penting yang harus diperhatikan ketika menggunakan warna, yaitu pemilihan warna khusus, nilai warna (tingkat ketebalan dan ketipisan warna itu dibandingkan dengan unsur lain dalam visual tersebut), dan intensitas atau kekuatan warna itu untuk memberikan dampak yang diinginkan.

9) Garis, dalam medium visual dapat dipergunakan untuk menyatukan unsurunsur visual. Di samping itu garis juga dapat digunakan untuk mengarahkan perhatian pada unsur-unsur informasi tertentu.

Kata Istilah dalam kamus besar Bahasa Indonesia adalah kata atau gabungan kata yang dengan cermat mengungkapkan makna konsep, proses, keadaan, atau sifat yang khas dalam bidang tertentu. Ilmu Alamiah Dasar (IAD) merupakan ilmu yang erat kaitannya dengan Ilmu Pengetahuan Alam dan Sains. Merupakan kumpulan pengetahuan tentang konsep-konsep dasar dalam bidang ilmu pengetahuan alam dan teknologi dalam manusia yang biasa disebut Natural Science (Maryanto, 2014:9). Ilmu alamiah merupakan ilmu pengetahuan yang mengkaji gejala-gejala dalam alam semesta, termasuk bumi ini, sehingga terbentuk konsep dan prinsip. Ilmu Alamiah Dasar hanya mengkaji konsep-konsep dan prinsip-prinsip dasar yang esensial saja (Nelly Wedyawati, 2010: 4).

Pengetahuan faktual merupakan pengetahuan yang harus dimiliki peserta didik jika mereka akan dikenalkan dengan suatu disiplin ilmu atau untuk memecahkan masalah apapun di dalamnya yang berkaitan dengan pernyataan yang benar karena sesuai dengan kenyataan yang sebenernya (Anderson \& Krathwohl, 2017:46). Pengetahuan faktual berkaitan dengan pernyataan yang benar karena sesuai dengan keadaan yang sesungguhnya.

Scrabble merupakan salah satu jenis permainan modern yang dapat digunakan dalam pembelajaran bahasa yang biasa disebut dengan spearsgame atau funworder (Soeparno, 1988: 75-76). Permainan scrabble ini ada kaitannya juga dengan silang datar yaitu dalam hal mengisi kotak-kotak dengan huruf sehingga membentuk sebuah kata. Daftar kata yang dibentuk dalam permainan scrabble ini harus merupakan kata yang mempunyai makna atau kata baku. Soeparno menambahkan peralatan untuk bermain scrabble sebagai berikut:

1) Papan karton berkotak-kotak yang terdiri atas berbagai warna. Warna-warna tersebut menentukan besar kecilnya nilai.

2) Kepingankepingan kayu atau plastik yang bertuliskan huruf, tiap-tiap huruf mempunyai nilai tertentu.

3) Tempat untuk menderetkan kepingankepingan kayu berhuruf itu agar dapat tegak sehingga pemain lain tidak dapat melihat huruf-huruf tersebut. 
Adapun cara melaksanakan permainan ini ialah sebagai berikut.

1) Jumlah pemain empat orang.

2) Setiap pemain sudah barang tentu harus menguasai peraturan permainan.

3) Secara bergiliran para pemain mengisi kotak-kotak yang tersedia.

4) Cara mengisi kotak-kotak hampir sama dengan silang datar. Jika pada silang datar kita harus menuliskan huruf, maka dalam scrabble kita tidak harus menulisnya lagi, akan tetapi cukup dengan menaruh kepingan-kepingan papan/plastik.

5) Kata-kata yang diisikan itu harus kata-kata yang ada didalam kamus, bukan kata seru, bukan singkatan, dan bukan nama diri. (Dalam penelitian ini kata-kata yang disikan, mengacu pada kata istilah yang terdapat pada materi Ilmu Alamiah Dasar)

6) Salah seorang siswa yang kebetulan tidak ikut bermian diminta mengawasi permaian sekaligus mencatat nilai dan harus selalu siap dengan kamus.

7) Apabila pemain dengan betul dapat menyusun huruf-huruf tersebut menjadi kata, maka ia akan mendapatkan sejumlah nilai. Perhitungan nilai didasarkan atas:

a) Banyaknya huruf yang dipasang atau panjang pendek kata yang disusun.

b) Besar kecilnya nilai setiap huruf.

$$
\begin{array}{lll}
\mathrm{Q}=10 & \mathrm{Z}=1 \mathrm{O} & \mathrm{H}=3 \\
\mathrm{X}=8 & \mathrm{~J}=8 & \mathrm{O}=1 \\
\mathrm{~K}=5 & \mathrm{~S}=1 & \mathrm{I}=1 \\
\mathrm{M}=3 & \mathrm{~A}=1 & \mathrm{~T}=1
\end{array}
$$

c) Letak huruf pada warna kotak.

8) Apabila ada pemain yang melakukan kesalahan, maka ia didenda sejumlah nilai yang mestinya akan ia peroleh. Kesalahan tersebut terjadi karena kata yang disusun tidak terdapat dalam kamus, kata salah ejaan, atau salah struktur morfologinya. Kesalahan struktur morfologis misalnya seorang pemain menambahkan afiks -s pada kata yang seharusnya tidak perlu menggunakan afiks -s tersebut.

9) Permainan diakhiri setelah semua huruf terpasang ata setelah para pemian tidak dapat lagi memasang huruf yang masih dimiliki. Pemenang ialah pemain yang dapat mengumpulkan nilai paling banyak (Soeparno, 1980:77).

Penelitian ini tidak melakukan model pengembangan pada media scrabble karena keterbatasan waktu dan adanya kesamaan kata istilah dengan bahasa inggris. Penulis mengharapkan untuk penelitian berikut, dapat dilakukan kajian pengembangan model terlebih dahulu untuk menentukan jumlah huruf yang sesuai dengan kata istilah.

\section{METODE PENELITIAN}

Penelitian ini adalah penelitian eksperimen semu, peneliti tidak mempunyai keleluasaan untuk memanipulasi subjek, artinya random kelompok biasanya dipakai sebagai dasar untuk menetapkan sebagai kelompok perlakuan dan control. Menurut Setyo (1997: 36) penelitian eksperimen biasanya diakui sebagai penelitian yang paling ilmiah dari seluruh tipe penelitian karena peneliti dapat memanipulasi perlakuan yang menyebabkan terjadinya sesuatu. Menurut Consuelo (1993: 93) penelitian eksperimen adalah satu-satunya metode penelitian yang dapat menguji hipotesis mengenai hubungan sebab akibat.

Penelitian ini menggunakan metode penelitian Kuantitatif pre-experimental designs, dengan desain penelitian the one group pretestposttest, dimana desain penelitian terdapat pretest sebelum diberi perlakuan dan posttest setelah diberi perlakuan. Dengan demikian dapat diketahui lebih akurat, karena dapat membandingkan dengan diadakan sebelum diberi perlakuan (Sugiyono, 2001: 64).

Kegiatan penelitian ini, bertujuan menilai perbedaan pengaruh penggunaan media scrabble secara berkelompok dan individual terhadap sebelum dan sesudah penggunaan media scrabble terhadap peningkatan pengetahuan factual kata istilah mahasiswa STAB Maha Prajna atau menguji hipotesis tentang ada tidaknya pengaruh perlakuan yang diberikan. Melalui penelitian eksperimen ini, peneliti ingin mengetahui bahwa penggunaan media scrabble secara berkelompok dan individual dapat meningkatkan pengetahuan factual kata istilah mahasiswa STAB Maha Prajna. 


\section{Rumus One Group Pretest-Posttest Design:}

\section{$\begin{array}{lll}\mathrm{O}_{1} & \mathrm{X} & \mathrm{O}_{2}\end{array}$}

Keterangan:

1. O1 merupakan pre test

2. X merupakan treatment

3. $\mathrm{O} 2$ merupakan post test

Hal pertama dalam pelaksanaan eksperimen menggunakan desain sampel tunggal ini dilakukan dengan memberikan tes kepada sampel yang belum diberi perlakuan, disebut pre test $(\mathrm{O} 1)$ untuk mendapatkan skor atau nilai pengetahuan faktual kata istilah pada materi Ilmu Alamiah Dasar. Setelah didapat catatan skor atau nilai, maka dilakukan treatment $(\mathrm{X})$ dengan teknik penggunaan media scrabble secara berkelompok dan individual untuk jangka waktu tertentu. Setelah dilakukan perlakuan kepada mahasiswa pengguna scrabble kelompok dan pengguna scrabble individu, maka diberikan lagi tes untuk mengukur tingkat pengetahuan factual kata istilah mahasiswa sesudah dikenakan variabel eksperimen (X). Dalam post test akan didapatkan data hasil dari eksperimen dimana pengetahuan factual kata istilah mahasiswa meningkat atau tidak ada perubahan sama sekali. Bandingkan $\mathrm{O} 1$ dan $\mathrm{O} 2$ untuk menentukan seberapa besar perbedaan yang timbul, jika sekiranya ada sebagai akibat diberikannya variabel eksperimen. Kemudian data tersebut dianalisis dengan menggunakan ttest (Arikunto; 2002).

Menurut Suharsimi Arikunto (2006: 101) populasi adalah keseluruhan subjek penelitian. Populasi merupakan sekumpulan individu yang mempunyai kesamaan karakteristik. Populasi dalam penelitian ini adalah seluruh mahasiswa semester 1, 3, 5, dan 7 Sekolah Tinggi Agama Buddha Maha Prajna Cilincing yang berjumlah 55 mahasiswa.

Sampel adalah wakil dari populasi. Pengambilan sampel ditujukan agar penelitian dapat berlangsung dengan efektif dan efisien. Karena sampel dipilih secara random yaitu seluruh mahasiswa semester 1 dan sebagian mahasiswa semester 3 maka teknik pengambilan sampel dalam penelitian ini menggunakan teknik probability sampling, yaitu menentukan sampel secara acak atau random dari populasi yang ada, yaitu semester 1 yang berjumlah 19 mahasiswa dan sebagian semester 3 yang berjumlah 11 mahasiswa.

Suharsimi Arikunto (2002: 136) instrumen penelitian adalah alat atau fasilitas yang digunakan peneliti dalam pengumpulan data agar pekerjaannya lebih mudah dan lebih baik. Pengumpulan data dalam penelitian ini adalah dengan tes pengukuran. Instrumen tes yang digunakan untuk pengukuran awal (pretest) maupun pengukuran akhir (posttest) menggunakan soal-soal esai pengetahuan factual kata istilah. Untuk memperoleh data mengenai pengetahuan factual kata istilah pada materi Ilmu Alamiah Dasar dari subjek penelitian, dilakukan dengan menjawab soal esai sebanyak 48 soal. Cara pelaksanaan test esai, yaitu:

1. Tujuan: mengetahui skor atau nilai pengetahuan faktual kata istilah materi Ilmu Alamiah Dasar

2. Perlengkapan: Pertanyaan, lembar jawaban dan alat tulis

3. Petugas: Membagikan soal, lembar jawaban dan alat tulis. Mengawasi mahasiswa mengerjakan esai

4. Pelaksanaan: dengan aba-aba "mulai", semua peserta mengerjakan soal esai tanpa alat bantu apapun dan dikerjakan masingmasing.

5. Penilaian: menghitung jumlah benar dari jawaban mahasiswa yang dicocokkan dengan kunci jawaban. Jumlah benar dikalikan 100 dan dibagi jumlah soal untuk mendapatkan nilai.

Dari data yang diperoleh dari penelitian ini dilanjutkan dengan mengganalisis data kemudian ditarik kesimpulan dengan menggunakan statistik parametrik. Uji normalitas tidak lain sebenarnya adalah mengadakan pengujian terhadap normal tidaknya sebaran data yang akan dianalisis. Pengujian dilakukan tergantung variabel yang akan diolah. Pengujian normalitas sebaran data menggunakan Kolmogorov-Smirnov Test 
dengan bantuan SPSS 16. Menurut metode Kolmogorov Smirnov, kriteria pengujian adalah sebagai berikut:

1) Jika signifikansi di bawah 0.05 berarti data yang akan diuji mempunyai perbedaan yang signifikan dengan data normal baku, berarti data tersebut tidak normal.

2) Jika signifikansi di atas 0.05 maka berarti tidak terdapat perbedaan yang signifikan antara data yang akan diuji dengan data normal baku, berarti data tersebut normal (Gempur Safar, 2010: http: //exponensial. wordpress. com/2010/04/21/metode kolmogorov - smirnov - untuk - uji normalitas/).

Rumus

$$
\mathrm{D}=\operatorname{Maksimum}\left[\mathrm{Sn}_{1}(\mathrm{x})-\mathrm{Sn}_{2}(\mathrm{x})\right]
$$

Di samping pengujian terhadap penyebaran nilai yang akan dianalisis, perlu uji homogenitas agar yakin bahwa kelompokkelompok yang membentuk sampel berasal dari populasi yang homogen. Uji homogenitas menggunakan uji $\mathrm{F}$ dari data pretest dan posttest pada kedua kelompok dengan menggunakan bantuan program SPSS, yaitu dengan menguji perbandingan varians terbesar dengan varians terkecil dengan rumus:

$$
F=\frac{\text { Varian Terbesar }}{\text { Varian Terkecil }}
$$

Berdasarkan hasil perhitungan kemudian di konsultasikan dengan tabel $\mathrm{F}$, jika $F_{\mathrm{h}}$ lebih kecil dari $F_{\mathrm{t}}\left(F_{\mathrm{h}}<F_{\mathrm{t}}\right)$, berarti $\mathrm{H}_{0}$ yang menyatakan bahwa antara kedua kelompok menunjukan perbedaan atau memiliki varians yang sama di tolak sehingga dengan kata lain kedua varians tidak homogen. Taraf signifikan yang di kehendaki 5\% dengan $\mathrm{F}_{\text {tabel }}=\mathrm{n}$ terbesar -1 (pembilang) dan $n$ terkecil -1 (penyebut).

Pengujian hipotesis menggunakan uji-t dengan bantuan program SPSS 16, yaitu membandingkan mean antara kelompok 1 dan kelompok 2. Apabila nilai t hitung lebih kecil dari t tabel, maka Ha ditolak, jika t hitung lebih besar dibanding t tabel maka Ha diterima

\section{HASIL DAN PEMBAHASAN}

Penelitian ini dilakukan beberapa tahap di ruang kelas kampus STAB Maha Prajna yaitu: pada tanggal 3 Oktober 2020 untuk pretest, dan penyampaian kata istilah materi Ilmu alamiah Dasar. Tanggal 4 Oktober 2020 penelitian penggunaan pertama media scrabble secara berkelompok dan individual dilakukan. Tanggal 10 dan 11 Oktober 2020, dilakukan penggunaan media scrabble kedua dan ketiga kalinya secara berkelompok dan individual. Tanggal 17 Oktober 2020 dilakukan penggunaan keempat media scrabble secara berkelompok dan individual. Kemudian dilakukan posttes pada tanggal 18 Oktober 2020 di ruang kelas kampus STAB Maha Prajna. Subjek dalam penelitian ini, yaitu mahasiswa semester 1 berjumlah 19 orang dan semester 3 berjumlah 11 orang dengan total peserta 30 orang yang setelah pretest dibagi menjai dua kelompok yaitu kelompok 1 dan kelompok 2. Tes pengetahuan actual kata istilah diambil sebanyak dua kali, yaitu pretest dan posttest. Pretest bertujuan untuk mencari reliabilitas, merangking, dan membandingkan dengan hasil postest. Postest dilakukan setelah mahasiswa melakukan penggunaan media scrabble secara berkelompok untuk kelompok 1 dan secara individual untuk kelompok 2. Tes dilakukan 4 kali kesempatan dan diambil nilai yang terbaik menggunakan pengetahuan faktual test. Dengan demikian diperoleh data dalam melakukan tes pengetahuan factual kata istilah saat pretest dan posttest Mahasiswa STAB Maha Prajna Jakarta. 
Tabel 1. Hasil Pretest dan Posttest pengetahuan faktual kata istilah kelompok penggunaan media scrabble secara berkelompok.

\begin{tabular}{|l|c|c|c|}
\hline Nama & $\begin{array}{c}\text { Nilai } \\
\text { Pretest }\end{array}$ & $\begin{array}{c}\text { Nilai } \\
\text { Posttest }\end{array}$ & Selisih Nilai \\
\hline MH 1 & 21 & 56 & 35 \\
\hline MH 2 & 29 & 58 & 29 \\
\hline MH 3 & 11 & 44 & 33 \\
\hline MH 4 & 6 & 43 & 37 \\
\hline MH 5 & 58 & 73 & 15 \\
\hline MH 6 & 19 & 56 & 37 \\
\hline MH 7 & 33 & 60 & 27 \\
\hline MH 8 & 21 & 62 & 41 \\
\hline MH 9 & 8 & 44 & 36 \\
\hline MH 10 & 56 & 80 & 24 \\
\hline MH 11 & 19 & 56 & 37 \\
\hline MH 12 & 60 & 90 & 30 \\
\hline MH 13 & 36 & 73 & 37 \\
\hline MH 14 & 17 & 60 & 43 \\
\hline MH 15 & 38 & 62 & 24 \\
\hline Rata2 & $\mathbf{2 8 , 8}$ & $\mathbf{6 1 , 3}$ & $\mathbf{3 2 , 3 3 3 3 3}$ \\
\hline
\end{tabular}

Tabel 2. Hasil Pretest dan Posttest pengetahuan faktual kata istilah kelompok penggunaan media scrabble secara Individual

\begin{tabular}{|c|c|c|c|}
\hline Nama & $\begin{array}{c}\text { Nilai } \\
\text { Pretest }\end{array}$ & $\begin{array}{c}\text { Nilai } \\
\text { Posttest }\end{array}$ & $\begin{array}{c}\text { Selisih } \\
\text { Nilai }\end{array}$ \\
\hline MH 16 & 44 & 80 & 36 \\
\hline MH 17 & 21 & 73 & 52 \\
\hline MH 18 & 67 & 100 & 33 \\
\hline MH 19 & 52 & 86 & 34 \\
\hline MH 20 & 48 & 82 & 34 \\
\hline MH 21 & 63 & 98 & 35 \\
\hline MH 22 & 52 & 86 & 34 \\
\hline MH 23 & 6 & 52 & 46 \\
\hline MH 24 & 33 & 62 & 29 \\
\hline MH 25 & 38 & 71 & 33 \\
\hline MH 26 & 29 & 66 & 37 \\
\hline MH 27 & 23 & 66 & 43 \\
\hline MH 28 & 63 & 96 & 33 \\
\hline MH 29 & 36 & 70 & 34 \\
\hline MH 30 & 86 & 100 & 14 \\
\hline Rata2 & $\mathbf{4 4 , 0 6 6 6 7}$ & $\mathbf{7 9 , 2}$ & $\mathbf{3 5 , 1 3 3 3 3}$ \\
\hline
\end{tabular}

Penelitian ini bertujuan untuk mengetahui pengaruh penggunaan media scrabble secara berkelompok dan individual terhadap peningkatan pengetahuan faktual kata istilah mahasiswa STAB Maha Prajna, hasil penelitian tersebut dideskripsikan sebagai berikut:

1. Pretest dan Posttest pengetahuan faktual kata istilah kelompok penggunaan media scrabble secara Berkelompok

Hasil penelitian tersebut dideskripsikan menggunakan analisis statistik deskriptif sebagai berikut, untuk hasil pretest nilai minimal $=6$, nilai maksimal $=60$, rata-rata $($ mean $)=28,8$, nilai tengah $($ median $)=21$, nilai sering muncul (modus) $=19$ dan 21, dengan simpang baku (std. Deviation) $=17,813$, sedangkan untuk posttest nilai minimal $=$ 43 , nilai maksimal $=90$, rata-rata $($ mean $)=$ 61,3 , nilai tengah (median) $=60$, nilai sering muncul (modus) $=56$, dengan simpang baku (std. Deviation) $=13,309$. Secara rinci dapat dilihat dalam tabel berikut:

\begin{tabular}{|c|c|c|c|c|c|}
\hline \multirow{2}{*}{ No } & \multirow{2}{*}{$\begin{array}{c}\text { kelas } \\
\text { Interval }\end{array}$} & \multicolumn{2}{|c|}{ Pretest } & \multicolumn{2}{|c|}{ Posttest } \\
\hline & & $\mathbf{F}$ & $\%$ & $\mathbf{F}$ & $\%$ \\
\hline 1 & $5-20$ & 1 & $7 \%$ & 0 & $0 \%$ \\
\hline 2 & $21-36$ & 5 & $33 \%$ & 0 & $0 \%$ \\
\hline 3 & $37-52$ & 5 & $33 \%$ & 1 & $7 \%$ \\
\hline 4 & $53-68$ & 3 & $20 \%$ & 3 & $20 \%$ \\
\hline 5 & $69-84$ & 0 & $0 \%$ & 5 & $33 \%$ \\
\hline 6 & $85-100$ & 1 & $7 \%$ & 6 & $40 \%$ \\
\hline \multicolumn{2}{|c|}{ TOTAL } & 15 & $100 \%$ & 15 & $100 \%$ \\
\hline
\end{tabular}


Tabel 3. Deskripsi statistik Pretest dan Posttest pengetahuan faktual kata istilah kelompok penggunaan media scrabble secara berkelompok

\begin{tabular}{|l|l|l|}
\hline Statistik & Pretest & Posttest \\
\hline $\mathbf{N}$ & $\mathbf{1 5}$ & $\mathbf{1 5}$ \\
\hline Mean & 28,8 & 61,3 \\
Median & 21 & 60 \\
Mode & $19 \& 21$ & 56 \\
Std. & 17,813 & 13,309 \\
Deviaton & 6 & 43 \\
Minimum & 60 & 90 \\
Maximum & & \\
\hline
\end{tabular}

Sumber: data diolah (2020)

Deskripsi hasil penelitian pre-test dan posttest penggunaan media scrabble secara berkelompok juga disajikan dalam ditribusi frekuensi. Deskripsi hasil tersebut dapat dilihat pada tabel di bawah ini:

Tabel 4. Deskripsi Hasil Penelitian Pre-test dan Post-test penggunaan media scrabble secara berkelompok mahasiswa STAB Maha Prajna

\begin{tabular}{|c|c|r|r|r|r|}
\hline \multirow{2}{*}{ No } & \multirow{2}{*}{$\begin{array}{c}\text { kelas } \\
\text { Interval }\end{array}$} & \multicolumn{2}{|c|}{ Pretest } & \multicolumn{2}{c|}{ Posttest } \\
\cline { 3 - 6 } & 6 & \multicolumn{1}{l}{$\boldsymbol{\%}$} & \multicolumn{1}{l|}{ F } & \multicolumn{1}{l|}{$\%$} \\
\hline 1 & $6-20$ & 6 & $40 \%$ & 0 & $0 \%$ \\
\hline 2 & $21-35$ & 4 & $27 \%$ & 0 & $0 \%$ \\
\hline 3 & $36-50$ & 2 & $13 \%$ & 3 & $20 \%$ \\
\hline 4 & $51-65$ & 3 & $20 \%$ & 8 & $53 \%$ \\
\hline 5 & $66-80$ & 0 & $0 \%$ & 3 & $20 \%$ \\
\hline 6 & $81-95$ & 0 & $0 \%$ & 1 & $7 \%$ \\
\hline \multicolumn{2}{|c|}{ TOTAL } & $\mathbf{1 5}$ & $\mathbf{1 0 0 \%}$ & $\mathbf{1 5}$ & $\mathbf{1 0 0 \%}$ \\
\hline
\end{tabular}

2. Pretest dan Posttest pengetahuan faktual kata istilah kelompok penggunaan media scrabble secara Individual

Hasil penelitian tersebut dideskripsikan menggunakan analisis statistik deskriptif sebagai berikut, untuk pretest nilai minimal $=6$, nilai maksimal $=$ 86 , rata-rata $($ mean $)=44.07$, nilai tengah $($ median $)=44$, nilai sering muncul (modus) = 52 dan 63, dengan simpang baku (std. Deviation) $=20,74$, sedangkan pada saat posttest nilai minimal $=52$, nilai maksimal $=100$, rata-rata $($ mean $)=79,2$, nilai tengah $($ median $)=80$, nilai sering muncul (modus) $=66,86$ dan 100, dengan simpang baku
$($ std. Deviation $)=15,06$. Secara rinci dapat dilihat dalam tabel berikut ini:

Tabel 4. Deskripsi Hasil Penelitian Pre-test dan Post-test penggunaan media scrabble secara individual mahasiswa STAB Maha Prajna

\begin{tabular}{|l|l|l|}
\hline Statistik & Pretest & Posttest \\
\hline N & $\mathbf{1 5}$ & $\mathbf{1 5}$ \\
\hline Mean & 44,07 & 79,2 \\
Median & 44 & 80 \\
Mode & $52 \& 63$ & $66,86, \& 100$ \\
Std. Deviaton & 20,74 & 15,06 \\
Minimum & 6 & 52 \\
Maximum & 86 & 100 \\
\hline
\end{tabular}

Sumber: data diolah (2020)

Deskripsi hasil penelitian pre-test dan posttest penggunaan media scrabble secara individual juga disajikan dalam ditribusi frekuensi. Deskripsi hasil tersebut dapat dilihat pada tabel di bawah ini:

Tabel 5. Deskripsi Hasil Penelitian Pre-test dan Post-test penggunaan media scrabble secara individual mahasiswa STAB Maha Prajna

\section{Uji Normalitas}

Uji normalitas dimaksudkan untuk mengetahui apakah variabel-variabel dalam penelitian mempunyai sebaran distribusi normal atau tidak. Penghitungan uji normalitas ini menggunakan rumus Kolmogorov-Smirnov Z, dengan pengolahan menggunakan bantuan komputer program SPSS Versi 16 IBM. Hasilnya sebagai berikut.

Tabel 6. Uji Normalitas Data

\begin{tabular}{|c|c|c|c|c|}
\hline \multirow{2}{*}{$\begin{array}{c}\text { Uji } \\
\text { Normal } \\
\text { itas }\end{array}$} & $\begin{array}{c}\text { Presabbl } \\
\boldsymbol{e} \\
\text { Berkelo } \\
\text { mpok }\end{array}$ & $\begin{array}{c}\text { Scrabbl } \\
\boldsymbol{e} \\
\text { individ } \\
\text { ual }\end{array}$ & $\begin{array}{c}\text { Scrabbl } \\
\boldsymbol{e} \\
\text { Berkelo } \\
\text { mpok }\end{array}$ & $\begin{array}{l}\text { Scrabbl } \\
\boldsymbol{e} \\
\text { individ } \\
\text { ual }\end{array}$ \\
\hline P & 0,128 & 0,128 & 0,128 & 0,128 \\
\hline $\begin{array}{c}\text { Taraf } \\
\text { Signifik } \\
\text { asi }\end{array}$ & 0.05 & 0.05 & 0.05 & 0.05 \\
\hline Ket & Normal & Normal & Normal & Normal \\
\hline
\end{tabular}

Dari hasil tabel di atas dapat dilihat bahwa data dari semua variabel memiliki nilai $p$ (Sig.) $0.128>0.05$, maka semua variabel berdistribusi normal. Karena semua data 
berdistribusi normal maka analisis dapat dilanjutkan.

\section{Uji Homogenitas}

Uji homogenitas berguna untuk menguji kesamaan sampel yaitu seragam atau tidak varian sampel yang diambil dari populasi.

\begin{tabular}{|l|c|c|c|c|c|c|}
\hline \multirow{2}{*}{ kel. } & \multirow{2}{*}{ rata2 } & \multicolumn{5}{|c|}{ t-test } \\
\cline { 3 - 7 } & & $\begin{array}{c}\mathrm{t} \\
\text { hitun } \\
\mathrm{g}\end{array}$ & $\begin{array}{c}\mathrm{t} \\
\text { tabel }\end{array}$ & Sig. & $\begin{array}{c}\text { Mea } \\
\mathrm{n} \\
\text { Def }\end{array}$ & $\begin{array}{c}\text { Kena } \\
\text { ikan } \\
(\%)\end{array}$ \\
\hline Pre Test & 44,07 & 6,80 & 2,14 & 0,000 & 35,1 & 79,7 \\
3 & 9 & 5 & 0,2 & 3 \\
\hline Aa & 79,2 & & &
\end{tabular}

Kaidah homogenitas jika $\mathrm{p}>0,05$, maka tes dinyatakan homogen, jika $\mathrm{p}<0.05$, maka tes dikatakan tidak homogen. Hasil uji homogenitas penelitian ini dapat dilihat pada tabel berikut:

Tabel 7. Uji Homogenitas Data

\begin{tabular}{|l|c|c|c|c|c|}
\hline \multicolumn{1}{|c|}{ Kel } & $\begin{array}{c}\text { Levene } \\
\text { statistik }\end{array}$ & df1 & df2 & Sig. & Ket \\
\hline $\begin{array}{l}\text { Pre } \\
\text { Test } \\
\text { Post } \\
\text { Test }\end{array}$ & 0.214 & 1 & 28 & 0,836 & Homogen \\
\hline
\end{tabular}

Dari hasil tersebut dapat dilihat dari tabel Test of Homogeneity of Variances untuk nilai pretest dan posttest nilai sig. $\mathrm{p} 0.836>$ 0.05 sehingga data bersifat homogen. Oleh karena semua data bersifat homogen maka analisis data dapat dilanjutkan dengan statistik parametrik.

\section{Uji Hipotesis}

\begin{tabular}{|l|c|c|c|c|c|c|}
\hline \multirow{2}{*}{ kel. } & \multirow{2}{*}{ rata2 } & \multicolumn{5}{|c|}{ t-test } \\
\cline { 4 - 7 } & $\mathrm{t}$ hitung & $\begin{array}{c}\mathrm{t} \\
\text { tabel }\end{array}$ & Sig. & $\begin{array}{c}\text { Mean } \\
\text { Def }\end{array}$ & $\begin{array}{c}\text { Kenaikan } \\
(\%)\end{array}$ \\
\hline $\begin{array}{l}\text { Pre } \\
\text { Test }\end{array}$ & 28,8 & \multirow{2}{*}{7,83228} & 2,145 & 0,000 & 32,5 & $112,847 \%$ \\
\hline $\begin{array}{l}\text { Post } \\
\text { Test }\end{array}$ & 61,3 & & & & & \\
\hline
\end{tabular}

a. Perbandingan Hasil Pre-Test dan PostTest penggunaan media scrabble secara berkelompok

Tabel 8. Uji-t Hasil Pre-Test dan Post-Test penggunaan media scrabble secara berkelompok
Nb. Untuk kenaikan persentase kesuksesan memenuhi target, yaitu 71,2 (100-28,8) diukur dari selisih nilai tertinggi yang dapat dicapai dengan rata-rata nilai Pre Test. Maka kenaikan persentase pemenuhan target nilai 100 adalah nilai 32,5 dari 71,2 yaitu $45,65 \%$.

b. Perbandingan Hasil Pre-Test dan PostTest penggunaan media scrabble secara individual

\section{Tabel 9. Uji-t Hasil Pre-Test dan Post-Test penggunaan media scrabble secara individual}

$\mathrm{Nb}$. Untuk kenaikan persentase kesuksesan memenuhi target, yaitu 55,93 (100-44,07) diukur dari selisih nilai tertinggi yang dapat dicapai dengan rata-rata nilai Post Test. Maka kenaikan persentase pemenuhan target nilai 100 adalah nilai 35,13 dari 55,93 yaitu $62,81 \%$.

c. Perbandingan Post-Test penggunaan media scrabble secara berkelompok dan individu

\section{Tabel 10. Uji-t berdasarkan hasil Post Test}

\begin{tabular}{|c|c|c|c|c|c|}
\hline \multirow{2}{*}{ Kel } & \multirow{2}{*}{ rata2 } & \multicolumn{4}{|c|}{$\mathrm{t}$-test for Equality of means } \\
\cline { 3 - 6 } & $\begin{array}{c}\mathrm{t} \\
\text { hitung }\end{array}$ & $\begin{array}{c}\mathrm{t} \\
\text { tabel }\end{array}$ & $\begin{array}{c}\text { Sig. } \\
\text { (2tailed) }\end{array}$ & $\begin{array}{c}\text { Mean } \\
\text { Def }\end{array}$ \\
\hline $\begin{array}{c}\text { Post -Test } \\
\text { scrabble } \\
\text { berkelompok }\end{array}$ & 61,3 & & & & \\
\hline $\begin{array}{c}\text { Post -Test } \\
\text { scrabble } \\
\text { individual }\end{array}$ & 79,2 & 4,7324 & 2,048 & 0.370 & 17,9 \\
\hline
\end{tabular}

Berdasarkan analisis data hasil penelitian diperoleh peningkatan yang signifikan terhadap kedua kelompok yang diteliti. Pemberian perlakukan selama 4 kali pertemuan dengan frekuensi 2 kali semingggu memberikan pengaruh terhadap peningkatan pengetahuan faktual kata istilah terhadap kedua kelompok penelitian. pengetahuan faktual kata istilah mahasiswa STAB Maha Prajna pada materi Ilmu Alamiah Dasar pada kelompok pengguna scrabble berkelompok sebelum diberi perlakuan memiliki rerata nilai 28,8 . Setelah diberi perlakuan dengan metode pengguna scrabble berkelompok, pengetahuan faktual 
kata istilah memiliki rerata nilai 61,3. Sedangkan pengetahuan faktual kata istilah mahasiswa STAB Maha Prajna pada kelompok pengguna media scrabble berkelompok sebelum diberi perlakuan memiliki rerata nilai 44,07. Setelah diberi perlakuan dengan metode pengguna media scrabble individual, pengetahuan faktual kata istilah meningkat dengan rerata nilai menjadi 79,2. Berdasarkan analisis menunjukkan bahwa metode penggunaan media tersebut berpengaruh signifikan dalam meningkatkan pengetahuan factual kata istilah mahasiswa STAB Maha Prajna.

\section{KESIMPULAN}

Berdasarkan hasil analisis data, deskripsi, pengujian hasil penelitian, dan pembahasan, dapat diambil kesimpulan bahwa:

1. Ada perbedaan pengaruh penggunaan media scrabble secara berkelompok terhadap pengetahuan faktual kata istilah materi Ilmu Alamiah Dasar pada mahasiswa STAB Maha Prajna, ditunjukan dengan $\mathrm{t}$ hitung $7,83228>\mathrm{t}$ tabel 2,145 , dan nilai signifikansi $0.000<0.05$, dengan selisih nilai 32,5 .

2. Ada perbedaan pengaruh penggunaan media scrabble secara individual terhadap pengetahuan faktual kata istilah materi Ilmu Alamiah Dasar pada mahasiswa STAB Maha Prajna, dengan t hitung 6.809 $>\mathrm{t}$ tabel 2.145 , dan nilai signifikansi $0.000<0.05$, dengan selisih nilai waktu 35,13.

3. Penggunaan media scrabble secara individual lebih efektif daripada Penggunaan media scrabble secara berkelompok terhadap peningkatan pengetahuan faktual kata istilah materi Ilmu Alamiah Dasar pada mahasiswa STAB Maha Prajna, dengan selisih nilai posttest sebesar 17,9.

\section{SARAN}

Penelitian tentang prokrastinasi akademik sudha banyak dilakukan dengan menunjukkan data atau hasil berupa adanya prokrastinasi pada mahasiswa. Penelitian ini perlu ditindaklajuti dalam bentuk penelitian rutin setiap satu tahun sekali, sebagai bentuk statistis perkembangan rokrastinasi akademik di suatu tempat perkuliahan. Idealnya dengan banyak penelitian dan tindakan pencegahan prokrastinasi akademik, persentase prokrastinasi akaemik mahasiwa akan menrun setiap tahunnya. Meski menrima mahasiswa baru yang mungkin memiliki prokrastinasi akademik sangat tinggi, namun penerapan penanggulangan prokrastinasi dilakukan diawal setiap mahasiswa baru memulai perkuliahan diajaran baru. Sehingga prokrastinasi tersebut dapat ditekan sejak dini.

\section{DAFTAR PUSTAKA}

1. Arikunto, Suharsimi. (2006). Prosedur Penelitian Suatu Pendekatan Praktek. Jakarta: Rineka Cipta.

2. Azhar, Arsyad. (2009). Media Pembelajaran. Jakarta: Raja Grafindo Persada Rineka Cipta.

3. Hamalik, Oemar. 2015. Kurikulum dan Pembelajaran. Jakarta: Bumi Aksara.

4. Indriana, Dina. 2011. Ragam Alat Bantu Media Pengajaran. Yogjakarta: DIVA Press

5. Journal of Experimental Psychology: Diane F. Halpern, The World of Competitive Scrabble: Novice and Expert Differences in Visuospatial and Verbal Abilities: 2007, Vol. 13, No. 2, 79-94

6. Maryanto, dkk. 2014. Buku Guru Kelas V Tema 9 Lingkungan Sahabat Kita Buku Tematik Terpadu Kurikulum 2013. Jakarta: Kementerian Pendidikan dan Kebudayaan.

7. Ningsih, Cherleyrian., Sudarmanto, R. Gunawan., \& Darsono (2020, Februari). Pengembangan Scrabble Ekonomi sebagai Media Belajar Siswa SMA. Jurnal Cherleyrian Ningsih_1223031047.

8. Soeparno. (1980). Media Pengajaran Bahasa. Yogyakarta: IKIP Yogyakarta

9. Sudjana, Nana dan Ahmad Rivai. (2002). Media Pengajaran. Bandung: Sinar Baru Algesindo.

10. Suprihatiningrum, Jamil. 2013. Strategi Pembelajaran Teori dan Aplikasi. Ar-Ruzz Media. Semarang.

11. Suryani, Nunuk dan Leo Agung, (2012), Strategi Belajar Mengajar, Yogyakarta: Ombak 